\title{
RASTREABILIDADE NA CADEIA PRODUTIVA DO LEITE COMO VANTAGEM COMPETITIVA
}

\author{
Jamir Rauta* \\ Leandro José Paetzold** \\ César Augutus Winck ${ }^{* * *}$
}

RESUMO: Este estudo objetivou entender a rastreabilidade como instrumento de vantagem competitiva para a cadeia produtiva do leite, de forma a fortalecê-la junto aos seus atores e em relação ao mercado, especialmente o consumidor, incluindo o externo. A pesquisa utilizou abordagem qualitativa, através de um estudo de caso e entrevistas semiestruturadas em uma indústria de laticínios da região Oeste do Estado de Santa Catarina, Brasil. Identificou-se que a inserção da rastreabilidade para esta indústria foi uma sugestão do fornecedor da tecnologia e uma estratégia de marketing, mas que para sua implantação era preciso alto investimento, divulgação da ferramenta, geração de cultura sobre o assunto, correto trato das informações e mão de obra especializada. Concluiu-se que no Brasil são necessárias profissionalização e pesquisas, no que tange a novas tecnologias a um custo menor, bem como desenvolver atividades, demonstrando a importância e resultados da rastreabilidade, sobre a decisão de compra dos consumidores, considerando qualidade dos produtos e segurança alimentar.

PALAVRAS-CHAVE: Agronegócio; Competitividade; Leite; Segurança Alimentar.

\section{TRACEABILITY OF THE DAIRY PRODUCTION CHAIN AS A COMPETITIVE ADVANTAGE}

ABSTRACT: Traceability as a tool of competitive advantage for the dairy production chain is provided for its strengthening vis-à-vis its agents, taking the market into account, especially consumers, with special reference to the external market. Quality research based on a case study and half-structured interviews at a dairy plant in the western region of the state of Santa Catarina, Brazil, was undertaken. Inserting traceability was a suggestion of a technology supplier and a marketing

\footnotetext{
Doutorando em Agronegócios na UFRGS - CEPAN; Mestre em Administração pela UNOESC; Administrador. Brasil: E-mail: jamirrauta27@gmail.com

** Mestre em Administração pela UNOESC; Engenheiro Agrônomo. Brasil.

${ }^{* * *}$ Doutor em Agronegócios pela UFRGS; Docente e Pesquisador da UNOESC no Mestrado Profissional em Administração. Brasil.
} 
strategy. High costs, tool broadcasting, generation of culture on the issue, correct treatment of information and specially-prepared personnel were required. Results show that professionalism and research on new technologies at lower costs and the development of activities are required. The above demonstrates the importance and results of traceability on consumers' buying power, involving product quality and food safety.

KEY WORDS: Agribusiness; Competitiveness; Milk; Food safety.

\section{INTRODUÇÃO}

O agronegócio tem se apresentado como importante gerador de riqueza para o Brasil. Em 2013, o PIB brasileiro registrou $\mathrm{R} \$ 4,8$ trilhões, sendo que $\mathrm{R} \$ 1,1$ trilhões eram oriundos do agronegócio, ou seja, $22 \%$ do montante.

Dentro do setor pecuário, a cadeia produtiva do leite em 2013 registrou uma produção de 35 bilhões de litros/ano, gerando um Valor Bruto de Produção superior a $\mathrm{R} \$ 22$ bilhões (CEPEA, 2014). Como se percebe no Gráfico 1, a evolução na produção de leite no Brasil de 2005 a 2013 foi acentuada, registrando uma variação superior a $40 \%$.

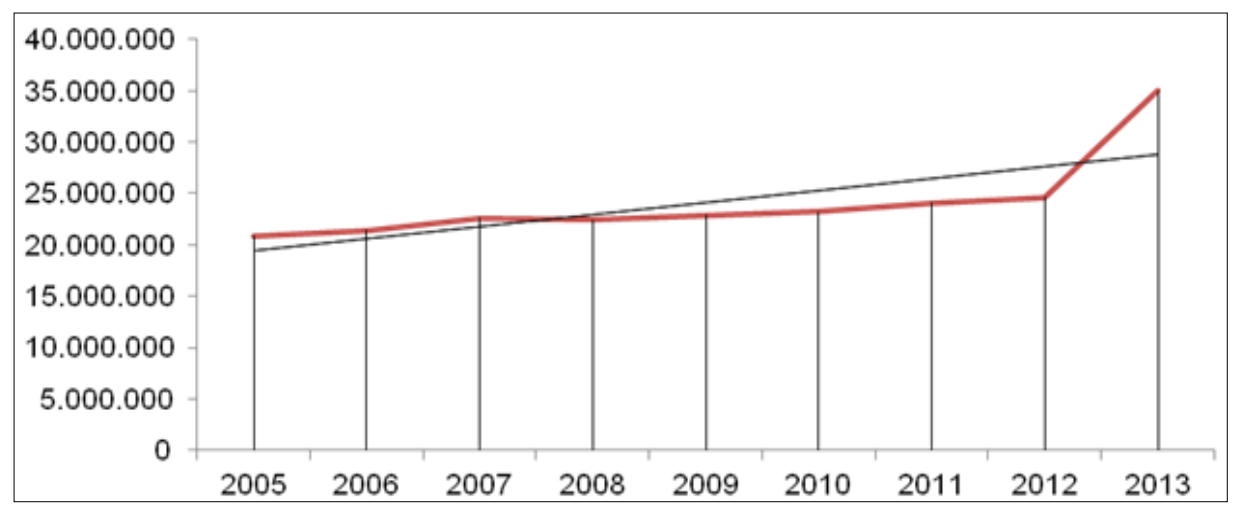

Fonte: ANUALPEC, 2014; CEPEA, 2014. 
Carvalho et al. (2007) prospectam a produção de leite para o ano de 2020 para em torno de 50 bilhões de litros, identificando-se que, para alcançar estes valores será necessário investir em escala de produção, melhoria na qualidade do leite e uso de tecnologias.

Todo este crescimento expõe o agronegócio brasileiro, neste caso, em especial a cadeia produtiva do leite, às pressões impostas pela globalização da economia, exigindo uma reestruturação fundamentada na eficiência, disponibilização de produtos com qualidade para o mercado a preço competitivo e acessível para o consumidor, de maneira que gere competitividade para os agentes envolvidos na atividade leiteira, e com vistas à segurança alimentar.

Os consumidores estão cada vez mais exigentes, considerando a aparência dos produtos, a qualidade nutricional, sanitária, sensorial, resíduos químicos, entre outros parâmetros. Portanto, há uma necessidade de atender ao controle da qualidade e origem dos produtos alimentares disponibilizados para o mercado, na busca por transparência nas condições de produção e comercialização.

A garantia de segurança alimentar e a redução de obstáculos ao comércio precisam ser conquistadas por um processo de harmonização das regulamentações sobre os alimentos e padróes de identidade e qualidade.

A produção na fazenda ou "dentro da porteira" (BATALHA, 2012) envolve o gado leiteiro e os produtores rurais. O setor pode ganhar maior eficiência quando são empregados elevados padrões de tecnologia que permitem aumentar a produtividade.

Entre os mecanismos importantes para aumentar a eficiência no processo produtivo destacam-se a sanidade, a alimentação e a genética, que caracterizam a parcela de responsabilidade do setor de insumos sobre a qualidade do leite (CANZIANI, 2003).

A busca pela qualidade tem mudado o nível de tecnologia nas unidades de produção, promovendo o uso de ordenhadeira mecânica e tanques de resfriamento. A indústria mudou o perfil de coleta de leite, adotando a granelização, e, ainda que de uma forma tímida, tem estimulado a adoção do pagamento com critérios baseados na qualidade (resfriamento, análise bacteriana e dos componentes) e volume de produção (OLIVEIRA, 2008; FIGUEIREDO; PAULILLO, 2006). 
Contudo, os produtores podem comercializar diretamente no mercado sem entregar para a indústria, conhecido como mercado informal. Segundo Canziani (2003), o mercado informal responde por quase $40 \%$ do leite comercializado. Esse mercado é utilizado, principalmente, pelos pequenos produtores que obtêm um maior preço do que intermediando a produção. Em meio a este ambiente competitivo, algumas situações surgem e trazem descrédito para toda a cadeia produtiva (OLIVEIRA; SILVA, 2012).

No entanto, quando o leite segue os canais comuns, as usinas de beneficiamento e as indústrias de laticínios ganham um papel importante na cadeia, justamente por serem responsáveis pela agregação de valor ao bem final, obtendo ganhos de escala e escopo a partir de parcerias e de integração vertical (CANZIANI, 2003).

Oliveira e Silva (2012) consideram o mercado do leite volátil e vulnerável por ser constituído de várias formas híbridas de governança e praticamente impossível estabelecer uma forma única de coordenação da cadeia via mercado ou integração total (vertical), devido às características produtivas do Brasil.

Outro aspecto relevante a destacar é a relação contratual entre usinas de beneficiamento e produtores de leite, pois como os preços são definidos pelo mercado, qualquer diferença entre preço das usinas e o preço de mercado poderá motivar ou desmotivar o produtor a entregar a produção à indústria.

$O$ registro da identificação de animais que entram na cadeia de produção de alimentos é importante e tem de ser encaminhada por todos os países internamente e também no mercado internacional, devido ao crescente desenvolvimento mundial do comércio de produtos agroalimentares. Esta demanda atual tem provocado o surgimento de normas e legislações adicionais nas áreas da qualidade, rastreabilidade e rotulagem dos alimentos.

Há ainda a certificação, instrumento que atesta determinadas características de um produto ou de um processo de produção, garantindo a procedência, o processamento e/ou a qualidade de um determinado produto, fornecendo ao produtor um diferencial e estabelecendo uma relação de confiança com o consumidor, agregando valor para o produtor, que coloca no mercado produtos com maior transparência para o consumidor, que por sua vez toma conhecimento 
de todas as práticas utilizadas na cadeia produtiva, sejam elas agrícolas, industriais, de sustentabilidade ambiental e responsabilidade social.

Dentro do contexto de transparência para o consumidor e a segurança alimentar, destaca-se a rastreabilidade (reconstrução das informações sobre procedência e característica do material utilizado em determinado produto, ficando armazenados para consulta quando for necessário) (CHAPAVAL; ALVES, 2013).

$\mathrm{O}$ conceito de rastreabilidade é recente no agronegócio, embora há mais de trinta anos já estivesse incorporado na gestão da qualidade das linhas de montagem da indústria aeroespacial, onde parece ter sido originada.

A rastreabilidade é a habilidade de traçar o caminho da história, aplicação, uso e localização de uma mercadoria individual ou de um conjunto de características de mercadorias, através da impressão de números de identificação (CHAPAVAL; ALVES, 2013), os quais são aplicados sobre itens individuais ou lotes, variam entre códigos, datas ou combinação disto.

A rastreabilidade é uma forma de prevenir a entrada de alimentos sem qualidade ou segurança, simplificar a localização de problemas (identificação dos locais/etapas que estão fora da normalidade, orientando a limites aceitáveis e na implantação de medidas para o controle), reduzir o volume de devolução de produtos (recall) e estabelecer responsabilidades (CHAPAVAL; ALVES, 2013; REZENDE FILHO, 2009).

O rastreamento ao longo da produção de leite, desde a ordenha até a obtenção do alimento pronto para o consumo, permite entender os diferentes fatores envolvidos e as ações corretivas e preventivas que podem ser implantadas de forma racional, garantindo a efetividade das boas práticas de fabricação e direcionar o treinamento dos colaboradores.

Rezende Filho (2009) identificou que as empresas podem ter interesse em adotar a rastreabilidade para fortalecer a demanda por seus produtos, pois os consumidores associam rastreabilidade a maior segurança do alimento ou que desejam saber a origem daquilo que consomem.

Os atributos são o principal estímulo que influenciam o consumidor em sua tomada de decisão de compra e são avaliados em função dos valores, crenças ou experiências passadas por consumidores, além de forma, característica, qualidade 
de desempenho, preparo, experimentação, custo, qualidade de conformidade, durabilidade, confiabilidade, comunicação ou mensagem explícita, facilidade de reparo, estilo, selos, certificações, rotulagem e marcas (KOTLER; KELLER, 2012; CUNHA; SPERS; ZYLBERSZTAJN, 2011).

É mediante esse cenário, principalmente aos pontos que retratam sobre a gestão da cadeia produtiva no agronegócio e segurança alimentar, que se insere o presente estudo, tendo como objetivo analisar a rastreabilidade como instrumento para geração de vantagem competitiva para a cadeia produtiva do leite.

\section{MATERIAL E MÉTODOS}

\subsection{MODALIDADE DA PESQUISA}

Este artigo possui uma abordagem qualitativa, feita através de estudo de caso com pesquisa bibliográfica e entrevistas semiestruturadas. Para Neves (1999), a pesquisa qualitativa constitui-se de um conjunto de técnicas de interpretação que buscam a descrição e a decodificação de fenômenos e sistemas em seus diversos componentes. Gil (2010) complementa dizendo que a pesquisa qualitativa trabalha com o aprofundamento da compreensão da causa e dos pesquisados.

Ao utilizar uma pesquisa qualitativa, o pesquisador envolve-se diretamente com a situação estudada na busca por dados que descrevam pessoas, lugares e processos e que permitam o entendimento da situação estudada pela visão que têm os sujeitos envolvidos (GODOY, 1995).

A busca pela compreensão transcende dados mensuráveis, provocando assim a leitura, segundo Minayo (2013), do universo de significados, motivos, aspirações, crenças, valores e atitudes, que estão intimamente ligados ao processo ou agentes envolvidos no estudo, e o autor complementa citando o ato de se aprofundar nas relações, processos e fenômenos que não podem ser reduzidos à operacionalização de variáveis. 


\subsection{DESCRIÇÃO DO OBJETO DE ESTUDO}

Entre os segmentos de atuação da empresa aqui estudada, encontrase o de lácteos. Sua planta industrial está instalada no Estado de Santa Catarina, Brasil, e sua área de abrangência (captação de leite) é todo o Oeste catarinense, parte do Sudoeste do Paraná e do Norte/Noroeste do Rio Grande do Sul. Por ter uma configuração de central de cooperativas, não possui cooperados (produtores) diretos. Esses estão ligados às cooperativas (filiadas) singulares.

É captada, diariamente, uma média de 1,2 milhão de litros. Desses, em torno de 600 mil litros utilizados para a produção de UHT (ultra high temperature) e o restante, por ordem de quantidade processada, para produção de leite em pó e queijo muçarela, seguidos pelos demais derivados, como nata, requeijão, creme de leite, bebidas lácteas, entre outros. Entre os itens formadores do preço/litro ao produtor está a qualidade.

Com base em pesquisa exploratória, bem como afirmação do gestor do laticínio, a empresa é pioneira no Brasil ao implantar o sistema de rastreabilidade na cadeia produtiva do leite, inclusive divulgando parte das informações ao consumidor via Internet.

\subsection{INSTRUMENTOS DA COLETA DE DADOS E PROCEDIMENTOS}

Pela busca de um entendimento mais prático, a partir de uma visão empresarial, e de forma que atenda o objetivo específico referente à vantagem competitiva, optou-se pelo estudo de caso e entrevista semiestruturada. Primeiramente aplicou-se um questionário com questões base para caracterização da organização em relação ao setor lácteo e depois uma entrevista semiestruturada com o gestor de qualidade do laticínio.

$\mathrm{O}$ artigo se construiu com dados secundários, vindos da pesquisa bibliográfica, que tem por objetivo o levantamento de referências teóricas já analisadas e publicadas por meios escritos e eletrônicos, como livros, artigos científicos, páginas de web e sites (FONSECA, 2002). Na sequência utilizou-se de dados primários, obtidos na entrevista em profundidade, realizada no fim de 
outubro de 2013, na planta industrial do laticínio.

As restrições do estudo foram o não acesso às informações estratégicas do laticínio e aos valores.

\section{RESULTADOS E DISCUSSÃO}

\subsection{IMPLANTAÇÃO DO SISTEMA DE RASTREABILIDADE}

A implantação do sistema de rastreabilidade no laticínio iniciou-se após sugestão de um fornecedor, o qual concedeu a tecnologia, quando da efetivação do processo. Perguntado ao gestor sobre o que fez a empresa investir no processo, o mesmo afirmou que foi por estratégia de marketing, seguido pela oferta do sistema, ou seja, uma variável externa, em conjunto com uma estratégia interna, resultou na implantação.

$\mathrm{O}$ investimento no processo de rastreabilidade no leite ocorreu pelo incentivo do fornecedor da tecnologia e, principalmente, para gerar maior confiança por parte do consumidor nacional e internacional, bem como pela segurança e qualidade do produto por parte do fornecedor (produtor de leite).

De certa forma, o laticínio se ajustou ao mercado através das normas e leis que existem sobre qualidade, reorganizou o processo produtivo, uniformizando e inserindo mais informações. Na sequência atrelou as estratégias de marketing, criando seu próprio programa de rastreabilidade.

$O$ requisito de identificação exigiu a criação de uma sistemática para visualizar o material ou item estocado ou em processo de fabricação por meio de marcações, etiquetas e documentos. Os produtos foram agrupados em unidades e lotes.

Para rastrear e controlar a conformidade do produto segundo o padrão preservou-se a ordem dos lotes, identificando ou separando-os de acordo com a causa comum. Cada lote recebeu um número específico, por trás desse existe um conjunto de documentos sobre a genealogia histórica dos materiais de entrada, as condições do processo durante a fabricação e os resultados dos testes do produto, 
resultando em um conjunto de documentos de toda a cadeia produtiva.

A Figura 1 apresenta em comunhão a cadeia produtiva do leite com $o$ processo de implantação e execução do processo de rastreabilidade pelo laticínio estudado. Destaque para união entre a estratégia interna de marketing e a oferta externa de tecnologia.

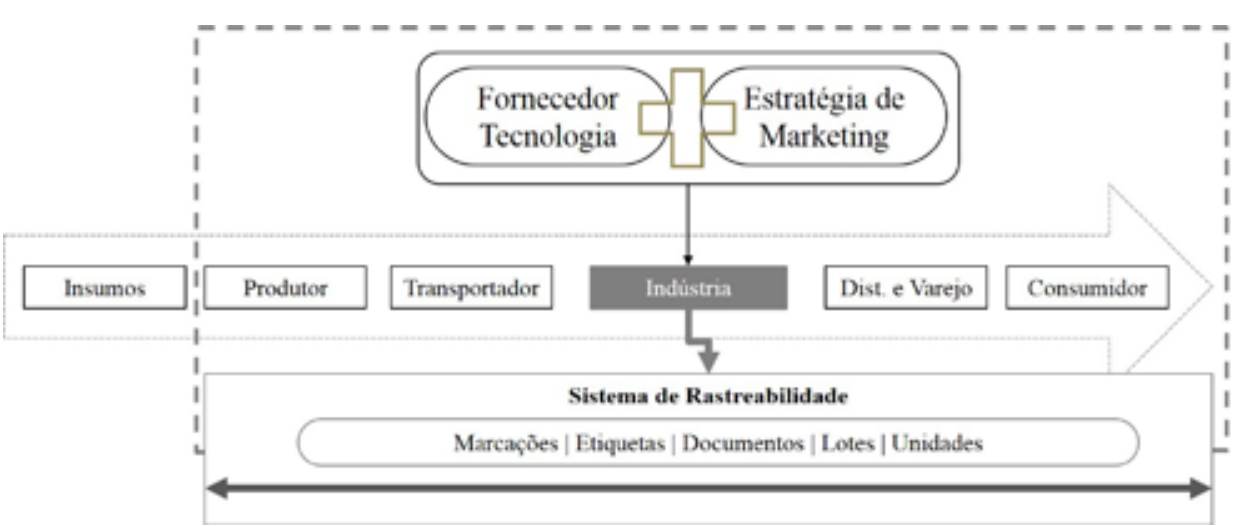

Figura 1. Cadeia produtiva do leite MAIS processo de implantação da rastreabilidade Fonte: Canziane,( 2003); Autor (2015).

A rastreabilidade descreve a vida dos produtos, em ciclos de entradas, processos e saídas (LAGO et al., 2009), determinando a melhor forma de apresentar a informação, que depende do contexto de sua utilização (LEAL JÚNIOR, 2011).

Para Kruchten (2003) cada empresa ajusta para sua realidade a implantação da rastreabilidade, utilizando-se de diferentes ferramentas, as quais têm por objetivo o suporte ao processo todo.

Em relação aos fatores identifica-se a rastreabilidade em um futuro próximo ajustando as empresas e formando redes estratégicas, possibilitando a redução de custos de transação por meio de ações de coordenação e negociação na cadeia de valor (JARILLO, 1988).

Marchi et al. (2012) identificaram que as redes estratégicas apresentavam mecanismos tanto nos aspectos de trocas de valor, compartilhando custos, como nos aspectos de criação de valor, compartilhando conhecimento, superando a ideia de centrais de compras, por ampliar as possibilidades competitivas no nível de cadeia, permitindo benefícios nos diversos elos. 
Porém, compartilhar custos na cadeia pode gerar vantagem competitiva momentânea ou de curto prazo. As possibilidades de compartilhamento de conhecimento trazem maiores e mais duradouras vantagens, pois oportunizam a melhoria e a inovação, sendo importantes diferenciais competitivos.

Mediante o entendimento entre o referencial teórico e a posição do laticínio estudado, surgem questões que vão além da relação venda versus compra. Se de um lado o laticínio investe em processo e tecnologia de rastreabilidade, partindo de uma estratégia de marketing, e de outro o consumidor deposita sua confiança na marca/produto do laticínio, acreditando que de fato esse produto tem qualidade ou outro benefício oriundo da rastreabilidade, surge então um custo além do negociado ou que pode agregar ao processo de negociação.

É o que, em 1937, Ronald Coase (COASE, 1988) nominou de custos de transação, definindo como o custo de usar o mecanismo de preço, o custo de realizar uma transação por meio da troca no mercado aberto ou custos de mercado.

Posteriormente, Williamson (1985) assumiu a teoria dizendo que os custos de transação podem ser do tipo ex-ante (custos de esboçar, negociar e salvaguardar o acordo) e ex-post (custos dos ajustamentos e das adaptações que resultam o rompimento contratual devido a falhas, erros ou ao interesse próprio de uma das partes).

Para North (1994) custos de transação são aqueles a que estão sujeitas todas as operações de um sistema econômico. Partilhando de sua visão, Neves (1999) cita que os custos de transação são os custos de efetuar uma troca, ou através da troca entre duas empresas no mercado ou a transferência de recursos entre estágios integrados verticalmente em uma mesma empresa, através da consideração de que a informação não é perfeita e tem custos.

Partindo dessas visões, todo custo de transação está relacionado a contrato. Direcionando ao objeto de estudo desse artigo, é possível falar que não existe um contrato formal e assinado entre o laticínio e o consumidor, mas um contrato "moralmente" firmado, novamente, na confiança, o que em algum momento irá gerar retorno financeiro para uma das partes.

Por outro lado e mediante as análises, percebe-se que no Brasil é preciso profissionalizar e intensificar as pesquisas sobre a rastreabilidade, principalmente em seu entendimento de importância e geração de resultados, para que mais empresas adotem-na em seus processos produtivos. 


\subsection{VANTAGENS E PROBLEMAS ENCONTRADOS NA IMPLANTAÇÃO DO SISTEMA DE RASTREABILIDADE}

Por entendimento do laticínio, o leite é uma commodity e que, em longo prazo, a rastreabilidade pode agregar valor ao produto, tanto para indústria quanto para o produtor, inclusive podendo abrir portas de outros mercados, principalmente os mais exigentes.

Por outro lado, o laticínio é ciente que a curto para médio prazo é somente questão de atendimento a legislação e de confiança junto ao consumidor, que está no final do processo produtivo e, portanto, distante do produtor. Esta visão é compartilhada por Naas (2005) ao ressaltar que tal distância é compensada através da comunicação de informações ao consumidor, papel da rastreabilidade, o que, de certa forma, contribui para geração de confiança.

Como barreiras para a implantação ficou evidente a questão tecnológica (por ser escassa e de altos investimentos), a questão cultural inexistente sobre a rastreabilidade e por último o trato das informações (manuseio, análise, interpretação e uso), existindo assim pouca mão de obra especializada para trabalhar com as informações.

Há duas categorias de instrumentos capazes de gerar e conservar a ideia de um produto de qualidade na cabeça do consumidor: os mecanismos de reputação (depende da imagem de marca que vai sendo construída no próprio mercado pela repetição das compras, onde quanto maior a reputação de uma marca de produto, maior é o prejuízo se a mesma for ameaçada) e os sistemas de certificação (um sinal de qualidade fornecido por instituições formais e independentes) (MACHADO, 2005).

A rastreabilidade, quando bem implantada, serve como um sistema de gestão para a propriedade produtora e seu fruto está em garantir a segurança alimentar, respeitando as leis sanitárias.

Por fim, a rastreabilidade oportuniza novas pesquisas, principalmente se forem direcionadas para o desenvolvimento de novas ferramentas, métodos e formas de aplicação. 


\subsection{GESTÃO DA QUALIDADE NO SISTEMA DE RASTREABILIDADE}

No quesito qualidade, o laticínio atendia ao que a legislação pedia. Neste sentido o gestor visualizava a rastreabilidade como um "motivador" para que o produtor e todo restante da cadeia produtiva igualmente estivessem focados na qualidade, o que se pode considerar como um gerador de vantagem competitiva.

$\mathrm{Na}$ opinião de Congro (2009), a rastreabilidade aparece como uma ferramenta importante e até mesmo necessária no processo de profissionalização da pecuária, de forma a garantir a qualidade do produto, seja ele como matéria-prima ou derivado.

Dentro desse contexto, a rastreabilidade contribui para verificação de irregularidades, facilitando ações corretivas e principalmente a construção de planejamento preventivo (AKABANE et al., 2010), visando à melhoria contínua e a qualidade dos produtos, cooperando com a segurança alimentar.

$\mathrm{Na}$ visão do gestor, a rastreabilidade é uma tendência a caminho de tornarse necessidade para as empresas, principalmente as vinculadas ao setor de alimentos. Por ser pioneiro no processo (rastreabilidade na cadeia do leite), o laticínio acredita ter criado uma vantagem frente à concorrência.

O gestor responsável pelo setor de qualidade do laticínio entendia que somente seria possível a continuidade do processo, bem como torná-lo uma estratégia institucional, se toda cadeia tiver incorporado a ideia e o objetivo da rastreabilidade. Por isso, salientava a importância do produtor entender sua propriedade como uma empresa e aplicar modelos de gestão para tal, ou seja, profissionalizar a produção.

A rastreabilidade, quando bem implantada, serve como um sistema de gestão para a propriedade produtora e seu fruto está em garantir a segurança alimentar, respeitando as leis sanitárias.

\section{CONSIDERAÇÕES FINAIS}

Para que a rastreabilidade se consolide no processo produtivo, necessitase conhecê-la e entendê-la através de pesquisas em cadeias distintas, pois ainda há certa insegurança e os custos para adesão são altos em função da tecnologia 
necessária, e com isso as empresas hesitam em aderir à rastreabilidade.

Percebeu-se que a indústria do estudo de caso acredita nos frutos que irá colher com a implantação da rastreabilidade, mesmo que a médio e longo prazo, porém, como é um assunto que a massa social não compreende exatamente, a empresa aguarda a conscientização e a inclusão de outras empresas no sistema.

Sugere-se que novas pesquisas sejam realizadas na compreensão por parte do consumidor ao termo rastreabilidade, e que sejam estimuladas as empresas e o governo a desenvolver ações de marketing que propiciem o esclarecimento sobre a importância de tal atividade e as melhorias que podem ser obtidas. Sugerem-se ainda pesquisas de formato quantitativo para medir de fato a percepção do consumidor e se está disposto a pagar mais por um litro de leite rastreado.

Para o laticínio sugere-se criar uma campanha formal, focada nos benefícios que a rastreabilidade pode proporcionar ao consumidor, aproveitando-se disso para agregar valor e se posicionar no mercado de forma competitiva. Por isso, por meio da interação empresa-cliente pode gerar maior valor, redirecionando sua oferta a diferentes mercados, alterando a forma, local de exposição e formando opinião.

É válido destacar que a rastreabilidade tem ainda que se desenvolver e se profissionalizar no Brasil, a tecnologia é escassa e o investimento alto, o que abre um campo vasto para pesquisas.

Já em relação ao laticínio, o que salvaguarda seu investimento é uma variável, talvez, imensurável e intrínseca, porém valiosa para os consumidores: a confiança.

Por fim, como resposta ao objetivo do estudo, é possível dizer que a empresa gerou vantagem competitiva, porém não financeira no primeiro momento.

\section{REFERÊNCIAS}

AKABANE, K. G.; LOPES, P. C.; SILVA, P. F. O sistema de rastreabilidade para a sustentabilidade no agronegócio brasileiro. Revista da Micro e Pequena Empresa, Campo Limpo Paulista, v. 4, n. 1, p. 80-95, 2010.

ANUALPEC - Anuário da pecuária brasileira. São Paulo: Instituto FNP, 2014. 
BATALHA, M. O. Gestão agroindustrial. 3. ed. São Paulo: Atlas, 2012.

CANZIANI, J. R. Programa empreendedor rural: cadeias agroindustriais. Curitiba: Senar, PR 2003.

CARVALHO, M. P.; MARTINS, P. C.; WRIGHT, J. T. C.; SPERS, R. G. Cenários para o leite no Brasil em 2020. Juiz de Fora: EMBRAPA Gado de Leite, 2007.

CEPEA. Relatório PIB - Agro Brasil 2013. Disponível em: < http://www.cepea. esalq.usp.br/comunicacao/Cepea_PIB_BR_dez13.pdf>. Acesso em: 20 out. 2014.

CHAPAVAL, L.; ALVES, F. S. F. Rastreabilidade na produção de leite de cabra: diferencial para um agronegócio sustentável. EMBRAPA Caprinos, 2008. Disponível em: $\quad$ <http://ainfo.cnptia.embrapa.br/digital/bitstream/item/92886/1/MidiaRastreabilidade-na-Producao-de-Leite-de-Cabra.pdf> Acesso em: 07 dez. 2013.

COASE, R. The firm, the market, and the law. Chicago: The University of Chicago Press, 1988. p. 33-55.

CONGRO, C. R. Sucesso da rastreabilidade bovina envolve quebra de paradigmas. Embrapa Pantanal. Disponível em: < http://www.embrapa.gov.br/ imprensa/noticias/2004/outubro/bn.2004-11-

CUNHA, C. F.; SPERS, E. E.; ZYLBERSZTAJN, D. Percepção sobre atributos de sustentabilidade em um varejo supermercadista. RAE, São Paulo, v. 51, n. 6, nov./ dez. 2011.

DICKINSON, D. L.; BAILEY, D. Meat traceability: are U.S. consumers willing to pay for it? Journal of Agricultural and Resource Economics, v. 27, n. 2, p. 348-364, 2002.

FIGUEIREDO, F. C.; PAULILLO, L. F. Gênese, modernização e reestruturação do complexo agroindustrial lácteo brasileiro. Revista Organizações Rurais Agroindustriais, v. 7, p. 173-187, Lavras, 2006. 
FONSECA, J. J. S. Metodologia da pesquisa científica. Fortaleza: UEC, 2002.

GIL, A. C. Como elaborar projetos de pesquisa. 4. ed. São Paulo: Atlas, 2010.

GODOY, A. S. Introdução à pesquisa qualitativa e suas possibilidades. Revista de Administração de Empresas, v. 35, n. 2, p. 57-63, mar./abr., 1995.

JARILLO, J. C. On strategic networks. Strategic Management Journal, Chicago, v. 9, n. 1, p. 31-41, jan./feb. 1988.

KOTLER, P.; KELLER, K. L. Administração de Marketing. São Paulo: Pearson Prentice Hall, 2012.

LAGO, P.; MUCCINI, H.; VLIET, H. V. A scoped approach to traceability

LEAL JÚNIOR, L. R. P. RAISE: um metamodelo de informação de rastreabilidade. 2011. 162f. Dissertação (Mestrado em Ciência da Computação) - Universidade Federal de Minas Gerais, Belo Horizonte, 2011.

MACHADO, R. T. M. Sinais de qualidade e rastreabilidade de alimentos: uma visão sistêmica. Organ. Rurais Agroind., Lavras, v. 7, n. 2, p. 227-237, 2005.

MARCHI, J. J.; CASSANEGO JUNIOR, P.; WITTMANN, M. L. Troca e criação de valor: possibilidades competitivas advindas da estratégia de redes. R. Adm., São Paulo, v. 47, n. 2, p. 180-196, abr./mai.jun. 2012.

MINAYO, M. C. S. Pesquisa social: teoria, método e criatividade. 33. ed. Petrópolis: Vozes, 2013.

NAAS, A. I. Rastreabilidade nas cadeias de aves e suínos: uma revisão. Revista Brasileira de Agroinformática, v. 7, n. 1, p. 1-7, 2005.

NEVES, M. F. Um modelo para planejamento de canais de distribuição no setor de alimentos. 1999. 296f. Tese (Doutorado em Administração) - Universidade de São Paulo, São Paulo, 1999. 
NORTH, D. C. Custos de transação, instituições e desempenho econômico. Rio de Janeiro: Instituto Liberal, 1994.

OLIVEIRA, L. F. T. Ambiente institucional e produção leiteira: um estudo de caso na região oeste catarinense a partir da introdução da IN51. 2008. Dissertação (Mestrado em Extensão Rural). Universidade Federal de Santa Maria, 2008.

OLIVEIRA, L. F. T.; SILVA, S. P. Mudanças institucionais e produção familiar na cadeia produtiva do leite no oeste catarinense. RESR, Piracicaba, v. 50, n. 4, out./dez. 2012.

REZENDE FILHO, M. A. Segurança do alimento e economia da rastreabilidade. Economia \& Tecnologia, a. 5, v. 17, p. 119-128, abr./jun. 2009.

WILLIAMSON, O. The economic institutions of capitalism: firms, markets, relational contracting. New York: The Free Press, 1985.

ZOCCAL, R. et al. Leite: uma cadeia produtiva em transformação. Juiz de Fora: Embrapa Gado de Leite, 2004.

ZYLBERSZTAJN, D.; NEVES, M. F. Economia e gestão dos negócios agroalimentares. São Paulo: Pioneira, 2000.

Recebido em: 22 de outubro de 2014 Aceito em: 14 de julbo de 2016 